\title{
Urgences
}

\section{Jardin de rocaille octobre}

\section{Gilles Leclerc}

Numéro 16, mars 1987

D.G. Jones : d'un texte, d'autres

URI : https://id.erudit.org/iderudit/025396ar

DOI : https://doi.org/10.7202/025396ar

Aller au sommaire du numéro

Éditeur(s)

Urgences

ISSN

0226-9554 (imprimé)

1927-3924 (numérique)

Découvrir la revue

Citer ce document

Leclerc, G. (1987). Jardin de rocaille octobre. Urgences, (16), 66-67. https://doi.org/10.7202/025396ar d'utilisation que vous pouvez consulter en ligne.

https://apropos.erudit.org/fr/usagers/politique-dutilisation/ 


\section{Gilles Leclerc JARDIN DE ROCAILLE OCTOBRE}

C'est sous la pluie

Un massacre d'ombres

$C^{\prime}$ est le cimetière des fleurs ${ }^{\mathrm{a}}$

C'est des faisceaux diaprés/bigarrés ${ }^{b}$

De feuilles mortes

Fleurs pourtant à mes yeux

Que ces pierres rassemblées

Telles des rangées de livres

Où s'entend toujours la voix

Des trépassés ${ }^{c}$

Sensation accrue/accentuée

De pierres dans ma bouche ${ }^{d}$

Et les cendres de mes pairs

Sont des fleurs

A mes yeux ${ }^{e}$

Est-ce le chaos

Le paradis

Angkor-Vat

Ou est-ce encore

Le coeur de la ville

Quand va sonner minuit?

Ici ni vie

Ni mort

Ni humanité $e^{1}$

J'y passe sous la pluie

Comme une ombre

C'est un jardin de mystères ${ }^{9}$ 
À la première lecture, j'ai pensé un moment qu'il pouvait s' agir là d'un "cimetière sous la pluie» et que les «rocks" (et «stones») étaient des pierres tombales, épitaphes ou stèles.

Ce n'est certes pas le plus beau poème de Jones.

L' «omicronisme» du texte (le "o» de "rock», le "o» de "stones", le "ou» de "ruin", entre autres) est patent, même si peut-être dû au hasard: rock, october, ruin, tomb, flower, colours, stones, tomes, more, full, bones, human, growth, runes; mais il donne au poème un accent de douceur, de résignation et de nostalgie.

"It gathers the colours/of fallen leaves»: prose de texte technique! Et cet «after/10 P.M.» est complètement antipoétique.

«Growth» m'a donné du mal: une forme, cinq ou six substances.

Le raccord ruin/runes est beau, aussi harmonique que mystérieux. Et rune est quasi intraduisible pour ce qu'il évoque dans le poème, car il signifie: 1) character of the runic alphabet; 2) charm, spell; 3) magic incantation; 4) mystery, secret; 5) poem, song, refrain. Quel sens poétique retenir? Je l'ignore, mais j'opterais pour une combinaison, une superposition des sens 2), 3) et 4).

Ce qui explique que j'y suis allé d'une vingtaine d'équivalents possibles, étant donnée l'imprécision poétique sous-jacente au mot en question, dernier du poème. Exemples:

a C'est/Ce sont sous le pluie

Des ruines d'ombres/Des ruines, des massacres d'ombres/Une jonchée d'ombres/Un effondrement d'ombres

C'est la sépulture, le sépulcre des fleurs

b Ce sont des îtots bigarrés/des monceaux colorés/des archipels colorés

c Que ces pierres assemblées

Tels des rayons de livres

Oũ s'achament à nous parler

Les morts/les disparus

d Sécheresse pierreuse/caillouteuse

De ma bouche

Accentuéelaccrue

ou Accrue/accentuée

Dans/de ma bouche

e Et épiphanie de fleurs

A mes yeux

Que les os de mes pairs

f Ce n'est ni la vie

Ni la mort

Ni même l'humanité

$\mathrm{g}$ C'est une profusion/une explosion/une floraison/une culture/une marée/une moisson de mystères ou C'est un parterre/un geyser de légendes/de secrets/de mythes 